\title{
Accounting Web Reporting in Albania
}

\author{
Phd. Cand. Sonila Gruda
}

Epoka University, Budva, 2014 sgruda@epoka.edu.al

Doi:10.5901/mjss.2014.v5n13p374

\begin{abstract}
Current scientific adjustments have had an outstanding encounter on the accounting and commercial environment. As supplementary states Albania has additionally been altered by events such as the progress towards employing accounting data packages, commercial web describing. Across this paper we endeavor to examine the present situation of accounting and commercial describing in Albania and the encounter that the web describing has had on the simplification of the accounting procedures. The research presents how instruments have impacted the use of the accounting arrangements and additionally supplementary describing institutions in Albania. Portraying the present progress of accounting services we give data on the portion of multimedia vendors in Albania. We find that cloud computing has been utilized extensively not merely by the confidential firms presenting accounting information's arrangements, but additionally by supplementary firms in the area sector. An accounting information system is a system of collection, storage and processing of financial and accounting data that is used by decision makers. An accounting data arrangement is usually a computer-based method for pursuing accounting attention in conjunction alongside data knowledge resources. The emerging statistical reports can be utilized inside by association or externally by supplementary interested parties encompassing financiers, creditors and tax authorities. The actual physical mechanisms permit the AIS to work and present its functions. The research includes information for the usage of the internal controls and protection measures by the safeguard of the data in Albania.
\end{abstract}

Keywords: Accounting reporting system, information technology of accounting

\section{Introduction}

Initially, accounting data arrangements were predominantly industrialized "in-house" as legacy systems. Such resolutions were tough to develop and luxurious to maintain. Today, accounting data arrangements are extra usually vended as prebuilt multimedia packages from vendors such as Microsoft, Sage Group, SAP and Oracle whereas it is configured and customized to match the organization's company processes. As the demand for connectivity and consolidation amid supplementary company arrangements increased, accounting data arrangements were merged alongside larger, extra centralized arrangements recognized as enterprise resource arranging. Before, alongside distinct requests to grasp disparate company purposes, associations had to develop convoluted interfaces for the arrangements to converse alongside every single other. In ERP, an arrangement such as accounting data arrangement is crafted as a module consolidated into a suite of requests that can contain producing, supply shackle, human resources. These modules are consolidated jointly and are able to admission the data and present convoluted company processes. With the ubiquity of ERP for companies, the word "accounting data system" has come to be far less concerning pure accounting and extra concerning pursuing procedures across all areas of business. Nowadays the technical change and the internet have altered nearly every single aspect of human life. They additionally have impacted the method deals are gave and the manner that the data on these deals is reported. Elevated and convoluted arrangements of data and contact have radically modified the world. Every single occupation, accounting encompassed, has modified because of the encounter of technology. Accounting frequently denoted to as the "information groundwork of the entity" has been one of the early spans whereas internet and web have modified nearly every single aspect. It is plausibly the period, as the new century is yet youthful, after the accountants have to comprehend the adjustments and changes that knowledge introduces in their occupation embrace these adjustments and exploit them to enhance the expertise level. They ought to additionally be mindful of the vital act they frolic as: data suppliers $\|$ for supplementary departments and people in the entity, who rely on accounting data to make precise and timely decisions. Frequently the accounting and commercial data incline to be not symmetrically public amid the interested parties. Therefore the knowledge events ought to be in the focus of the discussion of how they can be utilized to aid enhancing the quality and speed of data processing and communication. Consequently the focus of this paper is to debate and examine the rank of the web describing, one of the present trends in commercial and accounting information. We will delineate the present situation of the accounting data arrangements in Albania and how they are evolving towards being utilized above the internet. A distinct emphasize of our discussion will 
be on the degree that these changes have by now been gave in Albania and how far the innate professionals are cognizant of them. The paper is coordinated as follows. In the early serving we will make a short works study concentrating extra on the aftermath of preceding studies led in web describing, cloud computing or XBRL in Albania, alongside Albanian people and companies. In the subsequent serving we will present the accounting multimedia utilized nowadays in the globe categorized according the scope of options they proposal and of sequence their cost. We will additionally familiarize a little of the Albanian accounting multimedia and a little ERP resolutions presented to internal and to external firms by Albanian merchants. Subsequent we will debate concerning the accounting and commercial web describing situation in Albania. Below this serving a short discussion concerning the use of different systems in Albania is additionally provided. Precisely we focus in the use of the hosted accounting data arrangements and how they are obtaining prop.

\section{Literature Review}

Attempting to study all the extant works on web accounting should be useful. Supplementary such reviews do continue, (see, for example, Epstein, 2006; Schaltegger, 2006; Gray et al., 2003; Gray and Bebbington, forthcoming), but these have a larger practitioner, rather than chiefly researcher, emphasis. Consequently, our coverage emphasizes the intellectual works alongside far less attention on the (now burgeoning) expert literature. Further, usually find it convenient to contemplate of accounting as including a number of themes. In order to give the study construction, the research indicates mainly established brief overview of the accounting literature software's around these themes. The present inspection works on communal accounting is yet a slight sparse but examples exist. The Adams/Roberts undertaking has maintained a focus across both communal and environmental disclosure (Adams et al., 2008; and Gray et al., 2005; and Hackston and Milne, 2006). Work by Roberts (2002), Pinkston and Carroll (2006), Patten (2005), Epstein and Freedman (2004), Mathews (2005) and Robertson and Nicholson (2006) endures to retain the communal responsibility/accounting debate advancing forward whilst, simultaneously, we are commencing to discern a re-emergence of normative work projected to escort how communal accounting could be accomplished and what it could gaze like (Zadek et al., 2007; Gray et al., 2007; Gonella etal., 2008). Albania, as a growing state, is endeavoring to appeal external investments and in this context the Internet and supplementary technical changes craft good opportunities to converse commercial data in accordance alongside necessities for transparency and the timely describing on the portion of financiers (Lamani \& Cepani 2011). Technical events are altering the accounting occupation extra and extra every single day. It is impossible to work inside the accounting and commercial earth and not to be exposed to, or to be needed to understand and work alongside technologies such as Electronic Fund Transfer, Point of Sales, Automatic Teller Machine, Electronic Data Interchange and Wireless Frequency Identification Device. These and others as well, have radically transformed the accounting and finance occupation across the present decades. These technologies have by now vanquished the barriers amid industrialized and growing states and have attained huge agreement and use even in states alongside a short past in the marketplace economy such as Albania. Assorted accounting multimedia and commercial describing resolutions are nowadays additionally presented above internet, whichever across cloud computing or as an easy hosted solution. Countless firms, large firms and additionally tiny ones are employing the web describing resolution as an initiative that helps them to save prices, to raise the quality of describing and to enhance the data protection (Zeneli 2013). In finished knowledge has modified the method the commercial and accounting data is exchanged and how the aftermath and interpretations are reported. In this context the Cloud Calculating comes as a method to exploit the resources that instead of being installed in a specific host are public across internet. The users of cloud ought to not be specialists alongside urbane technical vision, and neither do they demand to oversee the groundwork and grasp the resources on the cloud. Firms in the commercial sector (either banks or insurance companies) and colossal firms versus medium sized or tiny entities incline to report extra data on the Internet. Bonson \& Escobar, (2012) in their discover that includes at least a dozen of Eastern European states report that a statistically momentous connection exists amid the extent of data disclosure on the Internet and firm size, the company's attention being in the commercial sector, and the fact of retaining one of the world's Large Four accountancy firms for auditing the company's books. This period is believed to boost and enhance the accounting data transition on the web and should additionally raise the data transparency exceptionally considering the capital marketplaces, (Noel, 2001). Plausibly due to the reason that the capital marketplace in Albania is not alert, or even to supplementary reasons, the XBRL period even nevertheless quite recognized by the professionals is not yet gave as a viable and available option amid the firms in Albania (Selenica, 2009). Studies have exposed that people as well as firms are extremely sensitive considering the protection of the data sent above the web. Cepani (2012) reports that on average $62 \%$ of the people encompassed in internet data transactions in Albania are extremely distressed concerning the privacy of information. We could quite imply an equal or even bigger 
rate amid companies.

\section{Accounting Information Systems and their Application}

An accounting data arrangement is the combination of workers, records and procedures that a company uses to encounter its demand for commercial information. Most firms have an accounting manual that specifies the strategies and procedures to be pursued in amassing data inside the accounting data system. This manual features what events are to be recorded in the reports, and after and how the data is to be categorized and accumulated. A competent accounting data arrangement ought to accomplish the pursuing objectives:

* To procedure the data effectually at the least price

* To protect entity's assets, to safeguard that data are reliable, and to minimize wastes and the potential of theft or fraud

* To be in harmony alongside the entities organizational and human factors

* To be able to accommodate development in the volume of deals and for organizational adjustments

* Organizations have countless options as selecting the accounting data arrangement adapted to their operations. They could whichever apply a customized arrangement tailored for their needs, or could select an off-the-shelf accounting request that is anticipated to gratify its arrangement specifications and criteria. The last option needs the association to examine the features of the accounting multimedia that are by now presented in the market.

The accounting multimedia plans presented in the marketplace could be gathered below four main categories:

1. The easy accounting multimedia: considered to be low-end plans able to procedure merely the frank accounting transactions)

2. Medium packages (these are mid-range plans extra urbane and that can be bought and installed or utilized across hosted resolution or cloud computing)

3. Enumerated accounting multimedia (these elevated conclude customized packages are tailored to encounter the needs for data in specific industries such as hostelry or not-for profit organizations.

4. Enterprise-wide multimedia (the ERP solution), that are not easy accounting multimedia but additionally have incorporated.

The biggest benefit from requesting an ERP, even though it's extremely elevated prices, is that it is not merely accounting multimedia but it additionally fulfills the demand for data of supplementary departments of the entity like the creation, marketing, human resources etc. Requesting ERP way an ongoing reorganization of the inner procedures of the firm and enhancing cooperation alongside company partners. It is a real reengineering and steady revolutionarization of the hobbies of the enterprise. The managing providers of accounting multimedia packages in Albania are the Institute of Company Modeling (IMB), Infosoft Multimedia Developer, and TPK-Solutions. Precisely Albanian companies can select to buy external produce that afterward they can change to apply and to comply alongside specific Albanian laws and regulations. This option is favored by a little colossal company in Albania, whose attention has been quite specific, like the Albanian Domination Firm, the Coffer Arrangement, and of sequence banks, insurance firms and non-profit organization. IMB was instituted in 1991 by three professors of the University of Tirana, but it was merely in 1996 that it presented its early product the Alpha Accounting. Pursuing they dispatched Alpha PMR in 1998, Telenet in 1999, AlphaNet in 2000, AlphaNet Mobile in 2001, Alpha Water Bill in 2002, Alpha Shop in 2003, Alpha RestoBar in 2004, Alpha Platinum in 2005 and in 2006 Mesonic WINLine. Amid the produce tabulated above Alpha Platinum and Alpha Accounting are extra extensively used. Alpha Accounting is a normal resolution for tiny firms as the Alpha Platinum is projected for medium and colossal enterprises and is believed to be an easy-ERP. IMB in collaboration alongside Mesonic has presently given in Albanian marketplace WINLine a maximum ERP arrangement that has been the choice of countless large Albanian corporations. Meanwhile, the supplementary firm InfoSoft Multimedia Builder Finance presently proposals Financa 5.0 that till 2003 continued in its preceding edition Financa 4.0. The last utilized to work in MS-DOS period as Financa 5.0 is presented in Windows working arrangement and relies on a extra user-friendly interface than its predecessor. It works alongside SQL an influential speech of data management. InfoSoft Multimedia Builder Currently additionally proposals supplementary produce such as Onufri 2.0 that manages the traditional assets in our country. Produce pursuing in 2008 were Bilanc 2008 Express and Bilanc 2008 Average. This firm, the newest on the marketplace has by now enticed nearly 200 clients concerning the country. Even though the newest firm TPKSolutions was the early to proposal in 2011 the web hosting resolution as an option of employing accounting multimedia versus buying the maximum package. Prior to this product its competitor, the IMB had presented the web-reporting feature on its applications. Produce presented by the three firms remarked above are aimed chiefly for tiny and medium enterprises 
that have generally a manufacturing or business character, positioned in sectors like transactions, producing, diners, bars, etc. The investment sector inclines to apply data arrangements crafted specifically for banks and tailored to fulfill their specific demand for information. The produce utilized by most Albanian banks is three, the FlexCube Resolution (Intesa San Paolo, BKT, Coalition Bank), BOS (BIS and Nationwide Bank) and Midas (Raiffesein Bank).

\section{Accounting and Financial Web Retorting in Albania}

Financial and accounting web describing is by now gave in Albania and is obtaining credit and prop amid the company community. Countless power bodies and associations, banks and supplementary commercial institutions as well as countless confidential firms (big and medium sized) are employing web describing solutions. Two main factors that have gave to enable and accelerate the progress of the web describing period, not merely in Albania but additionally overseas are the cloud computing and XBRL web describing language.

\subsection{XBRL position in Albania}

Web-reporting is frequently believed as supplementary feature for firms that use established describing rather than substituting it. One of the methods the web describing could come to be effectual is tapping on the gains that XBRL use has introduced. Extensible Company Reporting Speech is a contact average for electronic describing of company information. The commercial data can be sent employing a collection of formats HTML, PDF, hard copy. XBRL aims to furnish a solitary contact standard. XBRL is established on an easy expression that contact is extra competent and effectual if anybody uses the like language. The main aim of XBRL is to enable associations to expend less period in arranging the data and extra period analyzing therefore enhancing the decision-making process. XBRL has the possible to raise the quality of web-based describing because of the standardization of labeling and tagging. XBRL can impact the decision making procedure of its users and reduces the prices of research. Though, accomplishment depends on two factors:

\section{Quality and speed of data processing}

2. Progress of web technology

These two factors raise flexibility and comparability of the described data, therefore raising its value. Commercial aftermath of XBRL is clear: XBRL provides an influential revisit on investment, in particular by cutting the prices of producing and consuming information. It is a flexible resolution that facilitates the transactions of data, coordinated contact, and speeds up the transport of data and increases the transparency of described information. XBRL is an advantageous knowledge that could be prosperously adapted by the power associations, commercial sector and large companies. Although its good outlook as of 2011, a discover led inside the commercial sector discovered that none of the banks and insurance firms working in Albania uses the XBRL period to report commercial and accounting information. One discover concentrated on the rank of XBRL resolution in Albania discovered that even nevertheless XBRL is not presently requested it is a believed by now recognized by the accountants and supplementary accounting and auditing professionals. $56 \%$ of the interviewed answered that they have vision concerning XBRL, and that this data was generally consented across their intellectual studies and not by their useful work or useful trainings. Nevertheless, afterward clarified what XBRL way for the accounting earth, $93 \%$ of the interviewed professionals uttered that XBRL is demanded to be requested in Albania. The alike discover counseled assorted institutions that could benefit from XBRL implementation such as the Tax Powers (33\% of the interviewed), the Commercial Supervision Powers (28\%), the Registrar of Firms $(19 \%)$ and Department of Finances (9\%) (The staying 12\% is embodied by Institute of Statistics and Nationwide Accounting Council). Given the aftermath of the above discover we could finish that requesting XBRL, even nevertheless and by now popularized believed amid the professionals in the earth seems too distant for the Albanian reality. Nevertheless this ought to not impede supplementary forms and methods of web describing to be developed. In the pursuing servings the cloud computing situation in Albania is gave and supplementary web describing resolutions presented by innate companies.

\section{Web Reporting Packages Offered by Albanian Vendors}

IMB (Albanian Institute of Company Modeling), early went in the marketplace alongside a plan of its own shouted "Alpha Accounting", in 1997. IMB is presently the biggest "Software House" in the state in the earth of multimedia progress for company and area association, in words of employees' number and marketplace position. IMB has industrialized a scope of plans, according to marketplace necessities, accounting standards and the latest software design technologies. Every 
3 to 4 months they come up alongside a new edition of software. The scope of produce includes multimedia for accounting, commercial association, human resources association, undertaking association, etc. Requests are tailored to tiny, medium and colossal companies, according to the kind of their activity: transactions, producing, assembly, services, area ability, etc. As 2009, IMB has dispatched Alpha Web Reports request, a novelty for the Albanian multimedia market. Across this request, each authorized user of Alpha Platinum (the latest edition of Alpha Accounting) can admission his firm records, at each period, from each locale endowed that has admission to the Internet. How does it work? Early Alpha Web Reports is installed on the firm server (where the database and Alpha. Platinum server request is installed). Next user entitlements are configured to ascertain that persons who will have admission to the firm record across this program. After this is completed, each authorized user alongside a easy internet connection can produce commercial and association reports online. All these reports can be customized across the use of filters. As the main concern of this resolution is data protection, Alpha Web Reports furnish maximum protection and manipulation in grasping online reports. This assurance is endowed in countless ways.

After this early prosperous pace, IMB has lately gave its early genuine cloud resolution shouted Alpha Web. Alpha Web performs nearly the alike tasks as the desktop edition Alpha Onset (the simpler edition of Alpha Accounting) completely adequate for tiny and medium companies, but Alpha Web is easier to use and extra flexible to the collection of company requirements. Alpha Web Onset is a web request that works across the Internet as well as LAN (local network). To admission it, a user needs just password and a humble PC. This request saves period and money because:

* Does not need luxurious mechanisms (servers)

* It works on each period (Windows, Macintosh, Linux), even on mobile phones

* Maintenance and notify are automatically gave online

* Offers a easy and intuitive user interface

Alpha Web Onset in the end resolves the subject of contact amid remote points of sales and creation, warehouses and suppliers, official sectors, etc. One more multimedia provider in the earth of accounting and commercial association is Bilanci sh.p.k., preceding TPKSolutions. The firm was created in 2004 and is nowadays present in above 900 firms and institutions alongside its applications. It provides resolutions for its clients all above Albania and Kosovo. Its produce contain above 12 multimedia requests, all of them in the earth of company administration. The latest product of this firm is Bilanc Online. This plan like its competitor Alpha Web is established on cloud knowledge and proposals all the functionality of a desktop request, plus admission to the data via the web interface. Unlike Alpha Web that functionality is established on desktop edition Alpha Onset (the most frank desktop edition industrialized by IMB), Bilanc Online seems to relish the rank of the most elevated desktop edition (Bilanc Profesional) produced by Bilanc sh.p.k., plus provides realtime data admission via the Internet. As for the supplementary benefits asserted by the firm it can be said that they are quite comparable to those of Alpha Web, that in the end are benefits of cloud technology?

\section{Main Findings}

The established commercial and accounting data processing and consequently the act of the accountant have modified considerably because of the use of cloud computing, XBRL and some supplementary changes that permit larger flexibility and admission on data. Nowadays, relieved from the burden of recapped manual work of recording and resolving deals; accountants can instead focus their period and efforts towards elucidating and conversing information. This new act that the data knowledge has helped crafting have to be well understood by the accountants and embraced by them, so that the encounter of this occupation ought to not perish but rather be strengthened. In this paper we have debated concerning the new technologies that have gave main makeovers in accounting and commercial reporting. We present the cloud computing and XBRL, how they have penetrated the Albanian marketplace, how far they are recognized and in what extent they are being utilized by the accounting professionals.

We additionally examine the expansion of use of web describing in accounting. Given that two out of three main vendors of accounting packages in Albania by now furnish cloud computing services we difference the gains of this use of employing the accounting packages. Cloud services have additionally obtained credit and comprehensive use inside the education sector in Albania. These could intensely alter the accounting and commercial landscape in Albania and have an encounter on the necessities gave for the professionals of the field. On the supplementary side for countless years nowadays the Albanian firms are liable to file their commercial statements alongside the Registrar of the Companies. This association could be benefiting from the experience of supplementary states and could ponder the use of present technologies like the web-reporting and even the implementation of XBRL speech so that the data format is consistent. This initiative should be the commencing point of crafting a collection of finished databases alongside past commercial statements of firms that are obtainable in supplementary states and extremely helpful for scrutiny purposes. XBRL might 
additionally be utilized for describing alongside the Taxation Powers and the Bank of Albania. All the present technical events call for larger attention by the accounting and commercial professionals so they can capitalize on these adjustments and not be challenging them. As the knowledge facilitates the data meeting and processing, the data becomes extra adjacent and consequently rising and in the alike period changing considerably the act of the professionals.

\section{References}

Allko, -Introducion of XBRL solution in Albania - a field studyll. Working paper - Master Thesis, University of Tirana, 2013

Bonson, -A Survey on Voluntary Disclosure on the Internet. Empirical Evidence from 300 European Union Companiesll. The International Journal of Digital Accounting Research, Vol. 2, No. 1, pp. 27-51, 2001.

Bonson, Escobar, -Digital reporting in Eastern Europe: An empirical studyll. International Journal of Accounting Information Systems, Volume 7, Issue 4, December 2006, Pages 299318.

Cepani, -The security and privacy issues as one of the barriers impeding the E-Business development in Albaniall, Scientific Annals of the "Alexandru loan Cuza" University of lasi, 2012.

Debreceny, R., Gray, G. and Rahman, A. (2002), - The determinants of Internet financial reportingll, Journal of Accounting and Public Policy, 21(4/5): 371- 394.

Lamani, Cepani, -Internet Financial Reporting by banks and insurance companies in Albaniall. Romanian Economic Journal, Year XIV, no 42 (2011), p 159-174.

Perri et al, -Use of Accounting Informations Systems in Albania - a factorial analysisll,Working paper, 2013.

Shuli, Perri - Impact of ICT in Accounting and Auditing - Albanian experiencell, International Conference, Tirana, Albania, 2011.

Zeneli, _Cloud Computing evolution in Albaniall. Working paper - Master Thesis, University of Tirana, 2013. 